\title{
A autoconstituição do discurso filosófico sobre a verdade em tempos de pós-verdade
}

Jarbas Vargas NASCIMENTO

Marcel Fernandes GUGONI

O fato de que tantas pessoas estão irritadas com as mentiras de Trump mostra que nós ainda valorizamos e reconhecemos a verdade. [...] $A$ angústia com o discurso da "pós-verdade" é, em si mesma, uma indicação de que a verdade ainda está viva. ${ }^{1}$

GOLDHILL, Olivia. Um filósofo da verdade diz que não vivemos num mundo de "pós-verdade” afinal. Quartz, 19 ago. 2019

\section{Considerações iniciais}

Neste capítulo, propomo-nos trazer para o âmbito da Linguística e buscar, pela via da Análise do Discurso de linha francesa (AD), o modo como o discurso filosófico encena a verdade, nas condições sócio-históricas e culturais da pós-verdade. Objetiva-

1 Tradução nossa. Disponível em: <https://qz.com/1361505/a-philosopher-of-truth-says-were-not-living-in-a-post-truth-world-after-all/> 
mos analisar a constituência do discurso filosófico para, em seguida, identificar a cena enunciativa filosófica, seu enunciador e a forma como ele operacionaliza as estratégias linguístico-discursivas que legitimam esse tipo de discurso.

De partida, assumimos a verdade como uma certeza a respeito da realidade, de modo que ela, como conceito filosófico, se estabelece somente por meio de um enunciado lógico, que respeita as normas e os critérios ético e moral de nossa sociedade. Assim, um enunciado é verdadeiro, quando tais critérios estão de acordo com normas de funcionamento interno do discurso filosófico, e é falso, quando os rejeita (CHAUÍ, 2005).

Os gregos antigos tratam a verdade como tudo o que se baseia na correspondência entre o que pensamos e o mundo. Por isso, parece-nos natural assumir provisoriamente esse conceito de verdade. Em sentido mais estrito, a verdade se relaciona com a linguagem à medida em que materializa por ela nossas percepções. $\mathrm{O}$ erro e a mentira, por sua vez, referem-se a tudo o que não corresponde à realidade, tudo o que não se pode verificar ou confirmar na realidade.

Basta que consideremos o fenômeno contemporâneo da pós-verdade, para sermos colocados diante de uma nova situação, que tem suscitado pouco consenso, muitos embates, discussões e reflexões entre estudiosos, em diferentes áreas do conhecimento humano. Na pós-verdade, o erro e a mentira não só implicam posicionamentos discursivos, que subvertem a textualização da verdade, como levam a uma sobreposição dos fatos pela opinião - o que, de modo geral, atende a finalidades políticas.

De fato, é preciso reconhecer que "verdade e falsidade não estão nas coisas nem nas ideias, mas nas relações de correspondência entre coisas e ideias" (CHAUÍ, 2005, p. 101-102). Em outras pala- 
vras, verdade e falsidade dependem de posicionamentos linguístico-discursivos para serem analisadas. Portanto, qualquer tentativa de definição de verdade ou pós-verdade nos leva a operacionalizar enunciados, que articulam conceitos os quais, devido a propriedades linguísticas, permitem "categorizar o real ou o ser, integrando-os no domínio do dizível" (COSSUTTA, 1994, p. 50).

Nesse sentido, interessa-nos menos proceder a uma análise filosófica sobre os conceitos de verdade e mais entender o modo pelo qual o discurso filosófico, em sua enunciação discursiva, apreende esse conceito e define os procedimentos sociodiscursivos que determinam sua identidade. É por isso que visamos a examinar a constituência do discurso filosófico pela abordagem teórico-metodológica da Análise do Discurso de linha francesa (AD), nas perspectivas de Maingueneau (2000, 2006, 2008, 2010, 2014, 2018), de Cossutta (1994) e de Maingueneau \& Cossutta (1995). As contribuições teórico-metodológicas desses dois autores permitem apreender o discurso filosófico como um discurso constituinte, cuja característica é fundar e não ser fundado por outro discurso, conferindo sentido aos atos da coletividade e garantindo a existência de múltiplos gêneros de discurso. $\mathrm{O}$ discurso constituinte filosófico busca a universalidade e, para atingi-la, apaga as marcas de sua particularidade.

O corpus é um recorte do discurso "Verdade e política", produzido por Arendt (2016 [1954]), publicado em Entre o passado e o futuro, que discute a relação entre a verdade e a política, fundamentada por uma abordagem da Filosofia Política.

Nossa hipótese é de que, no discurso de Arendt, as estratégias linguístico discursivas evidenciam uma contradição entre verdade racional, fruto da razão e da própria construção do saber e verdade fatual, sujeita à disputa política por força da opinião, sendo essa a que melhor contrapõe à condição de pós-verdade. $\mathrm{O}$ argumento 
central do discurso de Arendt é a questão da verdade, tema que indicia o caráter filosófico de seu discurso.

Para dar conta dos objetivos propostos, organizamos este capítulo em três seções. Na primeira, situamos as condições de produção do discurso filosófico, que constituímos como corpus. Apresentamos, ainda, nessa seção, a emergência da verdade em uma era da pós-verdade, que se liga às próprias condições culturais, sociais e tecnológicas da contemporaneidade. Na segunda seção, tratamos de algumas das unidades de análise do discurso constituinte filosófico: interdiscurso, cenografia, ethos discursivo, código linguageiro e paratopia. Na terceira e última seção, procedemos à análise do corpus selecionado, a fim de indiciar as particularidades e a constituência do discurso filosófico.

\section{Ler Hannah Arendt na era da pós-verdade: condi- ções sócio-históricas de produção de um discurso filosófico}

A verdade está na ordem do dia em nossa sociedade; isso não quer dizer que estejamos mais conscientes de sua necessidade nas práticas cotidianas, no âmbito social; ou porque a requeiramos com mais veemência nas práticas políticas e econômicas, pelas vias da transparência e da boa gestão; ou, ainda, porque achamos que apenas ela possa sobreviver e que a mentira deixará de existir. A verdade interessa-nos porque, nas sociedades contemporâneas, ela ganha força em meio à ascensão de um fenômeno que visa a subverter a verdade: a pós-verdade. De partida, devemos considerar que se trata de mera ilusão a contraposição de verdade e pós-verdade, porque elas não são polos opostos de um fenômeno. 
Arendt (2016), em um artigo intitulado "Verdade e política", faz um percurso filosófico, a fim de refletir sobre o conceito de verdade. O resultado dessa reflexão foi publicado na revista The New Yorker, em 25 de fevereiro de 1967. A princípio, a autora esclarece que o ensaio é fruto de uma pseudocontrovérsia, que se seguiu à publicação de Eichmann em Jerusalém: um relato sobre a banalidade do mal, identificando nas reações ao livro uma "espantosa quantidade de mentiras utilizadas na 'controvérsia' - mentiras sobre o que escrevi, por um lado, e sobre os fatos que relatei, por outro" (ARENDT, 2016, p. 282). Na verdade, o livro de Arendt limita-se a expor fatos apresentados ao longo do julgamento de Adolf Eichmann, em 1961. Posta diante de fatos e interessada em relatá-los, Arendt se surpreende com críticas recebidas de que o livro não trataria de detalhes do processo, nem da atuação do general nazista, Eichmann, como cumpridor de suas tarefas nos campos de concentração. A controvérsia que ela aponta refere-se à discussão sobre a capacidade humana em emitir juízos.

Eichmann é um bom exemplo em nossos tempos de alguém que se deixou enganar, ao substituir sua consciência pelos ditames do Führer acerca de seus atos. Ainda que enxergasse em termos factuais o que estava fazendo, ele simplesmente não era capaz de discriminar sobre a natureza de suas ações, se criminosas ou erradas. (BACH; BARABACEZ, 2016, p. 72).

O momento de publicação tanto do ensaio quanto do livro era de polarização, em meio à Guerra Fria, em que conflitavam de modo notável modelos distintos de organização de Estado e de sociedade nos âmbitos político, econômico, cultural; e em que o totalitarismo era um fenômeno ainda a ser compreendido, anali- 
sado, criticado. Arendt fugira do totalitarismo nazista para, já nos Estados Unidos, tomar para si a tarefa de analisá-lo quanto a suas origens. As suas conclusões a respeito da organização política de um regime que trata o ser humano como descartável faz Arendt questionar a própria política, conforme manifesta Lafer (2016, p. 19), quando afirma que a reflexão de Hannah Arendt "elide o impasse do pensamento contemporâneo, retomando uma linha de tradição que [...] readquire um sentido que ficara ofuscado e afastado enquanto perdurou uma aspiração de totalidade sistemática”.

Arendt (2016) argumenta que a mentira é constitutiva da política e funciona como ferramenta necessária e justificável para sua ação, sendo considerada um instrumento mais inofensivo do que outros meios mais violentos. Para ela, verdade e política não convivem, porque aquela é contraproducente a esta, embora a natureza da verdade seja essencialmente política. A época moderna toma a verdade como algo que não é dado nem revelado - ao contrário da verdade da religião -, mas produzido pela mente humana - a exemplo das verdades racional e científica. Emergem desse raciocínio duas categorias de verdade. Em primeiro lugar, a verdade racional engloba as verdades matemáticas, científicas e as filosóficas e visa a iluminar o entendimento humano. Em segundo lugar, a verdade fatual engloba fatos e eventos e informa opiniões.

Ao tratar do que seria o oposto da verdade, Arendt (2016, p. 288) argumenta que:

[...] o contrário de uma asserção racionalmente verdadeira é ou erro e ignorância, como nas Ciências, ou ilusão e opinião, como na Filosofia. A falsidade deliberada, a mentira cabal, somente entra em cena no domínio das afirmações fatuais; e parece significativo, e um tanto es- 
tranho, que, no longo debate acerca desse antagonismo de verdade e política, desde Platão até Hobbes, ninguém, aparentemente, tenha jamais acreditado em que a mentira organizada, tal como a conhecemos hoje em dia, pudesse ser uma arma adequada contra a verdade.

A marca distintiva da verdade fatual consiste em que seu contrário não é o erro, nem a ilusão, nem a opinião - ao contrário da verdade racional, cujo contrário é erro, ilusão ou opinião -, mas a falsidade deliberada, as quais se incluem em um contexto interpretativo, de modo que a tentativa de apagar o registro histórico se traveste de opinião, assumindo sua legitimidade e reclamando sua fidedignidade. Por sua natureza, a verdade fatual é política, visto que "é sempre relativa a várias pessoas: ela diz respeito a acontecimentos e circunstâncias nos quais muitos estiveram implicados; é estabelecida por testemunhas e repousa em testemunhos; existe apenas na medida em que se fala dela, mesmo que se passe em privado" (ARENDT, 2016, p. 295).

A era da pós-verdade implica um tipo de manipulação da verdade fatual e da verdade racional. O prefixo leva-nos a crer numa supressão da verdade pela pós-verdade, mas o que esta indica é a superação dos fatos e da razão pela opinião, em uma tentativa dos enunciadores de enunciarem algo que é mais importante para si próprios do que a verdade: a ideia de que os sentimentos e as opiniões importam mais do que a realidade ou a razão.

Segundo McIntyre (2018, p. 62), trata-se de uma forma de supervalorização da subjetividade, cuja base se estabelece pela tendência que temos de "concordar com aquilo que outros à nossa volta acreditam, mesmo quando as evidências à nossa frente nos dizem o oposto". Em uma era de pós-verdade, a mentira e o engodo 
são enunciados como verdades, o que denota, por um lado, uma intenção do enunciador de contrariar os fatos de maneira deliberada e, por outro, uma relativa passividade do co-enunciador em ignorar os fatos para manter suas próprias opiniões.

A era da pós-verdade paira sobre diversos domínios da ciência, visto que há movimentos de negação de fatos relacionados a avanços científicos, a interpretações históricas, a notícias a interações nas redes, aos quais podemos atribuir termos como ciência falsa, história falsa, notícia falsa, perfis falsos (KAKUTANI, 2018).

\section{Discurso constituinte filosófico e a cena filosófica}

Desde sua constituição, dado seu caráter interdisciplinar, pesquisadores têm considerado a $\mathrm{AD}$ uma disciplina de entremeio, pois ela empreende um trabalho contínuo de reconfiguração de questões epistemológicas, trazendo para o interior dos estudos linguísticos, questões que inter-relacionam diferentes áreas do conhecimento e outras problemáticas que, em função de avanços do saber, necessitam de acréscimos, reconsiderações e novas reconfigurações. Essa é a hipótese de Maingueneau sobre a categoria discursos constituintes, que se inscreve em um programa de pesquisa que agrupa discursos fundadores. Esse agrupamento de discursos possibilita avanços no campo da $\mathrm{AD}$, já que é preciso considerar o modo específico de organização e funcionamento dos discursos constituintes e reportamo nos às condições de emergência, produção e circulação dos discursos literário, filosófico, religioso e científico, como propõe Maingueneau (2018).

Os discursos constituintes são capazes de autorizarem-se a si mesmos e a outros discursos, no tocante à produção simbólica da sociedade (MAINGUENEAU, 2000, 2006, 2008, 2010, 2014, 
2018). O discurso constituinte filosófico alimenta uma relação constitutiva com os valores fundadores de uma sociedade e elabora as condições de sua própria validade, fundando sua condição de emergência, funcionamento e circulação, ao lançar mão de sua própria autoridade, para estabelecer as condições de validade de seus enunciados e as condições de validação dos demais (COSSUTTA, 1994; MAINGUENEAU \& COSSUTTA, 1995).

Maingueneau (2018, p. 65) observa que "a obra filosófica [...] tende a absorver sua enunciação em seu enunciado, isto é, seu conteúdo doutrinal, reservando-se, todavia, a possibilidade de reverter sua doutrina em sua enunciação". Ainda, segundo Maingueneau (2018, p. 70-71), esse processo incide em três dimensões:

- o investimento de uma cenografia faz do discurso o lugar de uma representação de sua própria enunciação [...];

- o investimento de um código de linguagem, ao operar sobre a diversidade irredutível de zonas e registros da língua, permite produzir um efeito prescritivo que resulta da conformidade entre o exercício da linguagem que o texto implica e o universo de sentido que ele manifesta [...];

- o investimento de um ethos dá ao discurso uma voz que ativa o imaginário estereotípico de um corpo enunciante socialmente avaliado [...].

Cossutta, por sua vez, identifica recursos constitutivos materializados no discurso filosófico para produzir efeitos de sentido, entre os quais a necessidade de mediatizar a relação do particular com o universal e a de validar sua própria possibilidade enuncia- 
tiva. Esse procedimento se apresenta por meio de uma cena filosófica, "resultado desse trabalho de escrita pelo qual o filósofo representa o processo de pensamento no próprio âmago do texto [...], composta pelo conjunto das operações derivadas da estrutura enunciativa" (COSSUTTA, 1994, p. 14).

O discurso filosófico, para Cossutta (1994, p. 15), supõe a presença de uma função textual centrada na referência enunciativa sujeito, e é a

tentativa de abolir a própria noção de ponto de vista que se traduz por um dispositivo graças ao qual o filósofo se anula como que para deixar que a verdade fale por si; ele não fala em nome dela, não a busca, ele é o ponto de pura transparência em que a verdade se manifesta.

Assim, a inscrição do enunciador no discurso filosófico não se efetua somente pelos embreantes e pelos traços de subjetividade da linguagem, mas também em nome da razão, fonte legitimadora do discurso filosófico, na busca pela verdade. Segundo Maingueneau (2015), essa problemática discursiva associa a língua, ou seja, os recursos semióticos disponíveis em uma sociedade, à atividade comunicacional e aos diversos tipos de saberes, mobilizados na apreensão dos efeitos de sentido dos enunciados desse tipo de discurso. Dessa associação, decorre um equilíbrio entre o funcionamento do discurso, que contribui para a produção de efeitos de sentido e a compreensão de fenômenos de ordem sócio-histórica, que implica uma relação entre sujeitos e materialidade linguística em um dado tempo. Nessa perspectiva, o discurso se apresenta como uma forma de ação, decorrente de uma interatividade, que envolve um ou mais parceiros, que se colocam nessa ação como sujeitos. Além disso, o discurso só adquire sentido no interior do interdiscurso, 
isto é, de outros enunciados que se depreendem da memória do sujeito.

O discurso filosófico, como discurso constituinte, carrega um papel fundador na produção discursiva de uma sociedade, ao mesmo tempo em que confere sentido aos vários gêneros de discurso que nele/por ele circulam. Maingueneau \& Cossutta (1995) desenvolvem a categoria de discursos constituintes com base na hipótese de que alguns discursos, como o filosófico, autorizam-se a si mesmos. Maingueneau (2018), por um lado, dedica-se a levar essa noção adiante, ao tratar, mais particularmente, o discurso literário. Cossutta (1994), por outro lado, observa o discurso filosófico, a fim de identificar seus elementos de análise. Tratamos, nessa seção, das contribuições teórico-metodológicas desses autores, com a finalidade de analisar a constituência do discurso filosófico e identificar, na cena enunciativa filosófica, o enunciador e a forma de operacionalização de estratégias linguístico-discursivas, que legitimam o discurso filosófico.

A constituição de um discurso, segundo Maingueneau \& Cossutta (1995) envolve três dimensões: 1 . a ação de estabelecer, ensejando um processo pelo qual o discurso se instaura, construindo sua própria emergência no interdiscurso; 2 . o agenciamento de elementos que formam uma totalidade textual, permitindo observar seus modos de organização e de coesão discursiva; 3. o estabelecimento de um discurso que serve de norma e garantia dos comportamentos de uma coletividade. "De fato, a enunciação é empregada como dispositivo de legitimação do espaço de sua própria enunciação, de articulação de um texto a um modo de inscrição em um universo social.” (MAINGUENEAU; COSSUTTA, 1995, p. 115.)

2 Tradução nossa. 
Os discursos constituintes instauram-se por meio de uma relação constitutiva com a sede da autoridade de seu próprio discurso - o archeion (do grego archè, "fonte", "princípio", "poder") -, a qual "associa intimamente o trabalho de fundação no e pelo discurso, a determinação de um lugar associado a um corpo de enunciadores consagrados e uma elaboração da memória" (MAINGUENEAU \& COSSUTTA, 1995, p. 113). No caso do discurso filosófico, a sede da autoridade envolve a fundação dos conceitos, que são a própria enunciação, o lugar da ágora e seu corpo de enunciadores, isto é, os filósofos fundadores da doutrina ocidental e a elaboração da memória, que implica buscar esse corpo de enunciadores para enunciações posteriores.

Para Maingueneau (2000, p. 10), “o discurso constituinte não é um simples vetor de ideias, ele articula, através do dispositivo enunciativo, textualidade e espaço institucional", de modo que constrói na cenografia sua própria situação de enunciação, mobiliza um código de linguagem que lhe permite validar sua autoridade e confere a sua instância enunciadora um corpo, o que lhe fixa um ethos discursivo. A cenografia é instituída pelo próprio discurso e estabelece "um processo de legitimação da inscrição que traça um enlace paradoxal: o discurso implica um enunciador e um co-enunciador, um lugar e um momento de enunciação que validam a instância mesma que possibilita representá-los" (MAINGUENEAU \& COSSUTTA, 1995, p. 119). No discurso filosófico produzido por Arendt, a cenografia filosófica mobiliza um enunciador, um filósofo; um co-enunciador, um convidado a filosofar e a pensar sobre a verdade; um lugar, de um modo universalizante, pois o enunciador posiciona esse lugar nos Estados-nação contemporâneos; e um momento, que envolve uma reconfiguração política do pós-guerra em face à supressão dos totalitarismos europeus. 
Além da cenografia, Maingueneau (2010, 2014, 2018) observa que uma situação enunciativa se completa com a cena englobante, entendida como um tipo de discurso e com a cena genérica, um gênero de discurso que incita certo número de expectativas. Por isso, para um exame do discurso filosófico, devemos observar, também, a articulação ante a organização do discurso e suas condições sócio históricas de produção, a relação entre a representação de mundo e a enunciação, que são inseparáveis da forma como ele institui sua origem e circulação por meio da articulação entre a organização textual e a institucional que esse discurso pressupõe e estrutura. Sem dúvida, essas operações enunciativas instauram o discurso.

Sem aprofundar na distinção da cena de enunciação proposta por Maingueneau, Cossutta (1994) identifica a cena filosófica como o resultado do trabalho de escrita pelo qual o filósofo representa seu processo de pensamento. No discurso filosófico, são operacionalizadas, ao mesmo tempo, as marcas da enunciação filosófica, que referendam os enunciados a polos pessoais; as exposições, os encadeamentos e as argumentações resultantes de conceitualizações, que produzem marcas textuais de um aparelho formal da enunciação filosófica e as especificidades discursivas da enunciação filosófica, que demarcam as particularidades enunciativas de cada doutrina. Assim, de modo geral, a cena filosófica é marcada por uma perspectiva, por regras de construção que remetem a uma voz e a um corpo ausente e por um conjunto de representações que ela instaura.

O código linguageiro é mobilizado pelo discurso em função do universo de sentidos que procura impor (MAINGUENEAU \& COSSUTTA, 1995; MAINGUENEAU \& CHARAUDEAU, 2018). Isso implica gerir uma linguagem na interlíngua, o posicionamento adotado pelo enunciador em seu discurso e uma relação com a memória. "Longe de ser neutro, esse código é portador de uma di- 
nâmica e de valores historicamente situáveis." (MAINGUENEAU, 2018, p. 189.)

Em Cossutta (1994), podemos notar, na gestão da linguagem, dois aspectos fundamentais do discurso filosófico: a construção dos conceitos e das metáforas. Os conceitos constituem um intermediário entre a imagem e a forma, de modo que a filosofia constitui seu próprio vocabulário e se apropria das categorias oferecidas pela língua e pelas doutrinas anteriores. “O conceito filosófico apresenta-se como um operador textual que, graças a propriedades da língua, permite categorizar o real ou o ser, integrando-os ao domínio do dizível" (COSSUTTA, 1994, p. 50), de modo que cada conceito é agenciado de diferentes maneiras de acordo com a doutrina que o adota. Essa rede de conceitos constitui uma semântica conceitual, isto é, um conjunto de "operações através das quais o filósofo deliberadamente explicita a significação das expressões que ele emprega" (COSSUTTA, 1994, p. 42) e acrescenta que

O texto rearticula conjuntos nocionais, desloca sentidos fixados, cria expressões novas graças a um trabalho complexo de definições, de observações sobre o sentido, ou até mesmo de análises inteiras que fazem da explicitação semântica um dos meios de investigação filosófica. (COSSUTTA, 1994, p. 42).

As metáforas, por sua vez, cumprem um papel funcional de fornecer um equivalente concreto da análise filosófica, interrompendo a exposição abstrata e substituindo-a por outro plano de significação, caracterizado pelo emprego de imagens. "As analogias, comparações, alegorias, mitos, imagens e metáforas propriamente ditas baseiam-se no mesmo princípio e criam interferências no seio da complexidade textual. [...] O recurso metafórico está 
profundamente engajado na elaboração filosófica" (COSSUTTA, 1994, p. 103).

O ethos discursivo que emerge do discurso filosófico estabelece um corpo investido de valores historicamente especificados, o que implica uma maneira de dizer do enunciador que está associada a uma maneira de ser (MAINGUENEAU, 2008, 2010, 2014, 2018). $\mathrm{O}$ ethos emerge por meio de diferentes aspectos que são construídos por meio do discurso, que se ligam a um processo interativo de influência sobre o outro e que envolve um comportamento socialmente avaliado intrínseco a uma situação de comunicação precisa (MAINGUENEAU, 2018). No discurso filosófico de Aren$\mathrm{dt}$, o ethos não se refere à imagem da filósofa, mas ao sujeito que se posiciona na cenografia como antitotalitário, cujo estereótipo é de alguém que viu surgirem e desaparecerem os regimes fascista e nazista, uma corporalidade que se presentifica, no social, como uma mulher refugiada em decorrência de perseguição sociopolítico ideológica. A representação de uma filósofa imbuída da razão para reclamar o estatuto da ausência da verdade na política. Embora a noção de ethos discursivo pareça ser simples, ela envolve o ato de enunciação, conforme esclarece Maingueneau, quando postula que "o ethos é uma noção discursiva, é construído por meio do discurso, em vez de ser uma imagem do locutor exterior à fala" (MAINGUENEAU, 2018, p. 269).

Para Cossutta (1994), o esteio da cena filosófica se dá na referência enunciativa de um sujeito. Esse sujeito mostra uma imagem de si, que garante a unidade do discurso filosófico, sua coerência interna e sua possibilidade de referir-se ao mundo. Essa referência enunciativa "atribui papéis, distribui a fala e coordena os elementos de análise em um ponto de vista unificado" (COSSUTTA, 1994, p. 15). Além disso, o discurso filosófico visa a um co-enunciador, que funciona como "mediação entre o autor e ele mesmo, por um 
lado, e, por outro, entre a fonte enunciadora e a comunidade mais ampla que é visada" (COSSUTTA, 1994, p. 23).

Ao mesmo tempo que o ethos discursivo emerge como recurso distintivo, ele também ocupa um lugar problemático na sociedade, que são ao mesmo tempo um lugar e um não lugar. É o que Maingueneau $(1995,2008,2014,2018)$ chama de paratopia, uma condição necessária de todo discurso constituinte. "Se o locutor ocupa uma posição tópica, ele não pode falar em nome de alguma transcendência; mas se não se inscreve de alguma forma de alguma forma no espaço social, não pode proferir uma mensagem aceitável." (MAINGUENEAU \& CHARAUDEAU, 2018, p. 368369) Segundo Maingueneau (2018), o enunciador do discurso constituinte filosófico cria sua própria condição paratópica. No caso do discurso filosófico de Arendt, ela distancia sua produção e a própria filosofia do que é público e político para poder falar em nome da razão em busca da verdade.

\section{Análise do discurso constituinte e filosófico}

Com base nas reflexões anteriores e nas categorias de interdiscurso, discurso constituinte, enunciação filosófica, cenografia, ethos discursivo, código linguageiro e paratopia, nesta seção, fazemos a análise de recortes do discurso "Verdade e política", produzido por Arendt (2016 [1954]), e publicado em Entre o passado e o futuro, que discute a relação entre a verdade e a política, fundamentada por uma abordagem da Filosofia Política. Examinamos o modo como o discurso constituinte filosófico encena a verdade, nas condições sócio-históricas e culturais da pós verdade. Analisamos a constituência do discurso filosófico para, em seguida, identificar a cena enunciativa filosófica, seu enunciador e a forma de 
operacionalização de estratégias linguístico-discursivas, que legitimam esse discurso e compreendê-lo à luz do conceito de pós-verdade que vemos emergir na sociedade contemporânea.

\section{Recorte 1}

O tema destas reflexões é um lugar-comum. Jamais alguém pôs em dúvida que verdade e política não se dão muito bem uma com a outra, e até hoje ninguém, que eu saiba, incluiu entre as virtudes políticas a sinceridade. Sempre se consideraram as mentiras como ferramentas necessárias e justificáveis ao ofício não só do político e do demagogo, como também do estadista. [...] (ARENDT, 2016, p. 282-283).

O início do discurso "A verdade e a política” postula a asserção que dá norte a toda a reflexão filosófica que será desenvolvida dali em diante: "verdade e política não se dão muito bem". O enunciador argumenta sobre seu tema como um "lugar-comum", remetendo ao senso comum a noção de que a verdade não pertence à política e que a sinceridade não se enquadra nas virtudes políticas. Essa noção ativa, no interdiscurso, a dissociação entre política e verdade, a fim de explicitar a tensão entre as formações discursivas que associam a prática política à imoralidade ou à ausência de virtude, ao passo que exaltam a sinceridade e a verdade como valores morais pertencentes a campos aparentemente alheios à política. $\mathrm{O}$ interdiscurso também é acionado por meio dos embreantes "até hoje" e "ninguém", o que gera um efeito de sentido que remete à história do conhecimento ocidental, no qual não houve qualquer sujeito, ao longo de diversas momentos históricos, em inúmeras 
sociedades, que tenha desmentido o senso comum no que toca a asserção central desse recorte.

A associação de carga semântica negativa entre política e mentira é reforçada, em seguida, por meio da asserção de que a mentira, não a verdade, é uma "ferramenta necessária e justificável" ao ofício político, em que os adjetivos "necessária" e "justificável” apontam para a imanência da mentira como uma força motriz do andamento da política, bem como reforça a formação discursiva da política no sentido maquiavélico, de que à política importam os fins, independentemente dos meios a que se recorre para tal ação política.

O código linguageiro desse recorte aproxima os substantivos "político", "demagogo" e "estadista", que ainda que pertençam ao mesmo campo semântico da política, se diferenciam em graus de valor positivo ou negativo. Essa estratégia discursiva de aproximação não é fortuita, visto que o senso comum, em nossa sociedade contemporânea, associa a posturas de sentido negativo ou pejorativo tais comportamentos ou posturas do campo político.

Ainda nesse recorte, a embreagem subjetiva permite identificar a função autor ("que eu saiba"), de um sujeito que adere a um regime enunciativo com um sujeito de identificação (COSSUTTA, 1994), o qual se inscreve na própria enunciação exibindo o conteúdo de uma consciência que visa a uma generalidade, um alcance universal.

\section{Recorte 2}

[...] No transcurso da história, os que perseguem e os que contam a verdade tiveram consciência dos riscos de sua 
atividade; enquanto não interferiam no curso do mundo, eram cobertos de ridículo, porém aquele que forçasse seus concidadãos a levá-lo a sério, procurando pô-los a salvo da falsidade e da ilusão, encontrava-se em perigo de vida: "Se eles pudessem pôr as mãos em [tal] homem... o matariam", diz Platão na derradeira sentença da alegoria da caverna. [...] Não se menciona nenhum inimigo na estória de Platão; o povo vive pacificamente na caverna sem outra companhia, meros espectadores de imagens, sem estarem envolvidos em nenhuma ação e portanto ameaçados por ninguém. Os membros dessa comunidade não têm razão de espécie alguma para olhar a verdade e os contadores de verdade como seus piores inimigos, e Platão não oferece explicação de seu perverso amor pela falsidade e engano. [...] (ARENDT, 2016, p. 282-283).

Nesse recorte, estabelece-se a filiação do ensaio ao discurso constituinte filosófico, por meio de uma embreagem paratópica, pela polifonia e pelo uso de uma analogia. A embreagem paratópica inscreve esse enunciado em uma relação que reconhece o risco que corre o filósofo que busca a verdade, estabelecendo um lugar paradoxal ao inscrever o enunciador em um campo, "lugar de confronto entre posicionamentos" (MAINGUENEAU, 2018), ao mesmo tempo em que identifica a impossibilidade de o enunciador situar-se em uma sociedade que o expurga e o rejeita. De certo modo, essa paratopia também funciona como arquivo, remetendo a uma memória e uma instituição: ao referir-se a Platão e sua alegoria da caverna, o discurso estabelece uma embreagem filosófica, combinando um intertexto (Platão) a uma lenda (alegoria da caverna). Esse pertencimento paradoxal, em outra escala, recorre 
inicialmente a archeion, buscando sua autorização num arquitexto a respeito do lugar da verdade na sociedade. É possível reconhecer que esse discurso filosófico só pode dizer alguma coisa sobre o mundo ao questionar o próprio discurso filosófico que está em questão; com efeito, o enunciador, ao mesmo tempo que se aproxima do arquitexto e estabelece seu lugar de enunciação, se afasta desse arquitexto e reconhece o risco que corre ao tratar da verdade.

A polifonia articula a enunciação e os discursos precedentes, o que é perceptível pela predicação "diz Platão na derradeira sentença da alegoria da caverna”. A analogia permite personificar a asserção sobre o risco corrido por quem busca a verdade na política ao mesmo tempo em que constrói uma operação metafórica para assimilar dois planos discursivos (COSSUTTA, 1994): o do arquitexto e o do discurso filosófico. Tal operação não se exprime em totalidade, estando apenas composta como formação discursiva endereçada ao co-enunciador, que deverá completar por si mesmo a narrativa da alegoria da caverna para acompanhar o argumento do enunciador.

Mesmo assim, o enunciador se antecipa às eventuais lacunas do co-enunciador ao prover um questionamento ao próprio arquitexto, asseverando que "Os membros dessa comunidade não têm razão de espécie alguma para olhar a verdade e os contadores de verdade como seus piores inimigos, e Platão não oferece explicação de seu perverso amor pela falsidade e engano". Ilumina-se a contraposição entre a sociedade representada na alegoria e a sociedade contemporânea a respeito da ameaça que a verdade representa ao poder. A argumentação "Os membros dessa comunidade [da alegoria da caverna] não têm razão de espécie alguma para olhar a verdade e os contadores de verdade como seus piores inimigos" fornece incentivo para que o próprio co-enunciador busque seu oposto: o fato de que, na contemporaneidade, aqueles que fazem 
uso da mentira vejam a verdade e os contadores de verdade como seus piores inimigos.

De fato, em uma relação com o Recorte 1, podemos observar que o discurso filosófico, ao se preocupar com a verdade, atrai para si a inimizade dos ocupantes de posições de poder (políticos, demagogos e estadistas). Com efeito, podemos reconhecer que vale o mesmo raciocínio para a pós-verdade: quem a identifica como engodo ou mentira, tende a atrair a crítica de quem a enuncia.

\section{Recorte 3}

Embora as verdades de maior importância política sejam fatuais, o conflito entre verdade e política foi descoberto e articulado pela primeira vez com respeito à verdade racional. O contrário de uma asserção racionalmente verdadeira é ou erro ou ignorância, como nas Ciências, ou ilusão e opinião, como na Filosofia. A falsidade deliberada, a mentira cabal, somente entra em cena no domínio das afirmações fatuais; e parece significativo, e um tanto estranho, que no longo debate acerca desse antagonismo de verdade e política, desde Platão até Hobbes, ninguém, aparentemente, tenha jamais acreditado em que a mentira organizada, tal como a conhecemos hoje em dia, pudesser ser uma arma adequada contra a verdade. (ARENDT, 2016, p. 288).

Esse recorte estabelece os conceitos essenciais desse discurso filosófico. Interessa especialmente o estabelecimento de duas categorias de verdade: a verdade racional (fruto da razão e da pró- 
pria construção do saber manifestado em verdades matemáticas, científicas, filosóficas) e a verdade fatual (sujeita à disputa política por força da opinião). Assim, o enunciador cria seus conceitos, segundo um procedimento enunciativo que a própria cena filosófica estabelece. Sem dúvida, podemos notar ainda uma tentativa do enunciador desse discurso de equiparar a Filosofia à Ciência, de modo que caberia a ambos os discursos tematizar a verdade.

É possível observar que, ao proceder dessa forma, o enunciador estabelece o conceito de verdade racional no âmbito de dois discursos constituintes: o filosófico e o científico. Entretanto, ao tratar da "falsidade deliberada" e da "mentira cabal", aqui podemos observar dois aspectos primordiais: 1. As falsidades deliberadas e as mentiras cabais não se opõem diretamente à verdade fatual, mas tentam suplantá-la por meio do domínio discursivo das afirmações fatuais, funcionando dessa maneira como "arma adequada contra a verdade"; 2. É sobre esse ponto que a era pós-verdade emerge, como podemos notar pelo próprio discurso filosófico.

A verdade fatual "diz respeito a eventos e circunstâncias nas quais muitos são envolvidos; é estabelecida por testemunhas e depende de comprovação; existe apenas na medida em que se fala sobre ela, mesmo quando ocorre no domínio da intimidade. É política por natureza." (ARENDT, 2016, p. 295). Assim, a verdade fatual é a que mais interessa à política, pois é de fatos e eventos que se constitui a verdadeira textura do campo político. É sobre ela que o poder tende a estender suas garras, com a intenção de encobri-la ou de modificá-la. Isso porque "fatos e eventos são entidades infinitamente mais frágeis do que axiomas, descobertas e teorias [...] produzidos pelo cérebro humano" (ARENDT, 2016, p. 287).

Portanto, a marca distintiva da verdade fatual consiste em que seu contrário não é o erro, nem a ilusão, nem a opinião, mas a falsi- 
dade deliberada ou a mentira, as quais se incluem em um contexto interpretativo, de modo que a tentativa de apagar o fato se traveste de opinião, assumindo sua legitimidade e reclamando sua fidedignidade. A mentira, nesse aspecto, é uma ação diante do que é, de modo que o mentiroso age no e pelo discurso para substituir a verdade fatual por aquilo que não é. Eis o modo como o enunciador desenvolve o efeito discursivo da mentira: o mentiroso é livre para moldar seus "fatos", adequando-os às expectativas da audiência, o que tende a tornar a mentira mais convincente do que a verdade.

O resultado do processo de substituição da verdade fatual pela mentira não é a mentira ser aceita como verdade, nem a verdade ser difamada como mentira, mas a destruição do sentido mediante o qual nos orientamos no mundo. A era da pós verdade abarca esses fenômenos da falsidade deliberada e da mentira diante da verdade fatual, comprovada ou comprovável no e pelo discurso.

\section{Recorte 4}

[...] Conceitualmente, podemos chamar de verdade aquilo que não podemos modificar; metaforicamente, ela é o solo sobre o qual nos colocamos de pé e o céu que se estende acima de nós. (ARENDT, 2016, p. 325).

Observa-se neste recorte, que compõe o trecho final do discurso analisado, uma conceituação e uma metaforização cuja intenção parece ser a de estabelecer, em definitivo, um sentido para o que seja a verdade. Como vimos, é próprio do discurso filosófico recorrer a conceitos e a metáforas para enunciar. A metáfora é especialmente produtiva ao fornecer a imagem de "solo" e de "céu" 
para a verdade: opera-se, assim, uma substituição identificadora de imagens da realidade sensível, à qual o enunciador aproxima seu conceito.

A verdade fatual, nesse sentido, é perceptível pela coletividade e sobre ela é possível enunciar; a verdade fatual é insubstituível, ainda que possa ser obnubilada por inúmeros objetos sensíveis; a verdade fatual estabelece o limite dentro do qual se insere todo pensamento filosófico, toda elaboração discursiva, toda enunciação. A verdade fatual é tudo o que não podemos modificar. $\mathrm{Na}$ era da pós-verdade, uma grande parte das tentativas de superar a verdade visam mais a ludibriar os sujeitos do que a iluminar seu pensamento.

\section{Considerações finais}

No discurso de Hannah Arendt, pudemos observar os mecanismos de constituição, no âmbito do discurso filosófico, do conceito de verdade e identificar algumas das propriedades dos enunciados que validam esse conceito. Em uma era de pós-verdade, a verdade parece ser colocada em um segundo plano, à frente do qual a opinião e a subjetividade prevalecem.

O objetivo de analisar a constituência do discurso filosófico foi cumprido ao percorrermos os investimentos do discurso filosófico na cenografia, no código de linguagem e no ethos discursivo. De modo mais preciso, ao analisar a constituência do discurso filosófico de Arendt, notamos que o discurso se instaura e constrói sua própria emergência no interdiscurso, ao mesmo tempo em que, de modo mais notável, coloca-se como norma e garantia dos comportamentos de uma coletividade. No caso de uma reflexão sobre 
a verdade em tempos de pós-verdade, tais questões estão em negociação por diferentes sujeitos e seus posicionamentos.

Em segundo lugar, pudemos apontar para diferentes características e componentes da cena enunciativa filosófica, buscando identificar o enunciador e a forma de operacionalização de estratégias linguístico-discursivas que legitimam esse discurso.

Por fim, ao tematizar a relação da verdade com a pós-verdade, em uma perspectiva discursiva, refletimos também sobre o modo como os enunciados enunciam a realidade e como, em uma era de pós-verdade, muitos enunciados visam a subverter a verdade. Esperamos que esta reflexão contribua com o campo da $\mathrm{AD}$, ao jogar luz sobre uma temática atual, a fim de expandir as fronteiras de pesquisa sobre o discurso constituinte filosófico e da análise do discurso.

\section{Referências}

ARENDT, Hannah. Verdade e política. In: Entre o passado e o futuro. São Paulo: Perspectiva, 2016 [1954]. p. 282-325. BACH, Augusto; BARABACEZ, Maria Solange. Depois de nós: um estudo sobre verdade factual e ausência de reflexão (o sentido do mal e o juízo público a partir de Hannah Arendt). Kínesis, v. VIII, n. 18, dez. 2016, p. 57-81. Disponível em: <www.marilia.unesp.br/ Home/RevistasEletronicas/Kinesis/5_augustobach .pdf>. Acesso em: 26 jun. 2019.

CHAUÍ, Marilena. A verdade. In: . Convite à filosofia. São Paulo: Ática, 2005. p. 88-103. COSSUTTA, Frédéric. Elementos para a leitura dos textos filosóficos. São Paulo: Martins Fontes, 1994. KAKUTANI, Michiko. A morte da verdade: notas sobre a mentira da era Trump. Rio de Janeiro: Intrínseca, 2018. 
LAFER, Celso. Da dignidade da política: sobre Hannah Arendt. In: ARENDT, H. Entre o passado e o futuro. São Paulo: Perspectiva, 2016 [1972]. p. 9-27.

MAINGUENEAU, Dominique. Analisando discursos constituintes. Revista do GELNE, v. 2, n. 2, 2000. Disponível em: <https:// periodicos.ufrn.br/gelne/article/view/9331/6685>. Acesso em: 24 mar. 2019.

MAINGUENEAU, Dominique. Lénonciation philosophique comme institution discursive. Langages, ano 29, n. 119, 1995. Lanalyse du discours philosophique, p. 40-62. Disponível em: <www.persee. fr/docAsPDF/lgge_0458-726x_1995_num_29_119_1722.pdf $>$. Acesso em: 24 mar. 2019.

. Cenas da enunciação. São Paulo: Parábola, 2008.

. Doze conceitos em análise do discurso. São Paulo: Parábola, 2010.

Discurso e análise do discurso. São Paulo: Parábola, 2014. 2018.

MAINGUENEAU, Dominique. CHARAUDEAU, Patrick. Dicionário de análise do discurso. 3. ed. 3. reimpr. São Paulo: Contexto, 2018.

MAINGUENEAU, Dominique. COSSUTTA, Frédéric. Lanalyse des discours constituants. Langages, ano 29, n. 117, 1995. Les analyses du discours en France. p. 112-125. Disponível em: <www. persee.fr/docAsPDF/lgge_0458-726x_1995_num_29_117_1709. pdf $>$. Acesso em: 24 mar. 2019.

MCINTYRE, Lee. Post-truth. Cambridge, MA: MIT Press, 2018. 